\title{
Non alcoholic steatohepatitis is associated with subclinical impairment in left ventricular function measured by speckle tracking echocardiography
}

\author{
Ahmet Oğuz Baktır, Bahadır Şarlı, R. Emre Altekin1, Ahmet Karaman* , Hüseyin Arınç, Hayrettin Sağlam, \\ Yasemin Doğan, Abdulsamet Erden**, Hatice Karaman***
}

Departments of Cardiology, *Gastroenterology, **Internal Medicine and ***Pathology, Kayseri Education and Research Hospital; Kayseri-Turkey ${ }^{1}$ Department of Cardiology, Faculty of Medicine, Akdeniz University; Antalya-Turkey

\section{ABSTRACT}

Objective: Nonalcoholic steatohepatitis (NASH) is a part of histological spectrum of nonalcoholic fatty liver disease (NAFLD). Higher incidence of cardiovascular mortality has been reported in studies including patients with NAFLD. Impaired myocardial function can be detected by a novel echocardiographic method called speckle tracking echocardiography (STE) when conventional methods were normal.

Methods: Twenty-eight biopsy-proven NASH patients (mean age 41.6 $\pm 9.8,16$ male) without hypertension and diabetes mellitus were included in study. All patients underwent transthoracic echocardiography. Offline analyses of images was performed and strain (S), strain rate (SR) parameters compared between NASH patients and controls. Statistical analysis were done by independent samples t test between groups and a multiple linear regression model was used to identify the statistical significance of relationships between selected variables.

Results: $R_{S R-S}$ values were similar but $R_{S}, R_{S R-E}, R_{S R-E / A}$ values were significantly lower and $R_{S R-A}$ was higher in the NASH patients. There were no significant differences in $\mathrm{C}_{S}, \mathrm{C}_{\mathrm{SR}-\mathrm{S}}, \mathrm{C}_{\mathrm{SR}-\mathrm{E}}, \mathrm{C}_{\mathrm{SR}-\mathrm{A}}$ and $\mathrm{C}_{\mathrm{SR}-\mathrm{E} / \mathrm{A}}$ values among the two groups. The most impressive results were obtained from longitudinal strain and strain rate parameters. $L_{S}, L_{S R-S}, L_{S R-E}, L_{S R-A}$, values were significantly lower in NASH group when compared with healty controls. Linear regression analysis showed that RS and LS was not associated with diastolic blood pressure, total cholesterol and LDL cholesterol.

Conclusion: The LV longitudinal and radial systolic functions may be deteriorated in patients with NASH even in the absence of apparent decrease in the LV ejection fraction. STE may be useful in detecting preclinical LV impairment in patients with NASH. (Anatolian J Cardiol 2015; 15: 137-42)

Key words: nonalcoholic steatohepatitis, speckle tracking echocardiography, subclinical myocardial dysfunction, nonalcoholic fatty liver disease

\section{Introduction}

Nonalcoholic steatohepatitis (NASH) is a part of histological spectrum of nonalcoholic fatty liver disease (NAFLD) and may progress to cirrhosis in $15-20 \%$ of individuals within one or two decades (1). Conventional and novel risk factors for cardiovascular disease are commonly observed in NAFLD patients. Higher incidence of cardiovascular mortality and severity of coronary artery disease reported in studies including patients with NAFLD $(2,3)$. In these studies NAFLD was associated with abnormal diastolic functions and left ventricular structure (4). NASH is an advanced form of NAFLD, characterized with histological changes in liver. Cardiovascular morbidity and mortality is increased in patients with NASH.

2-D speckle tracking is a novel echocardiographic method that determines myocardial deformation from continuous frame- by-frame tracking of speckles called as 2-D speckle tracking echocardiography (2-D STE) which is angle independent and can assess the magnitude and timing of regional and global ventricular deformation in different directions (5).

Previous studies usually investigated NAFLD patients who were diagnosed by, a qualitative assessment method, abdominal ultrasound, and conventional echocardiographic methods like tissue Doppler echocardiography $(4,6)$. Differently in this study, we aimed to investigate the presence of subclinical myocardial systolic and diastolic dysfunction using 2-D STE, in patients with NASH diagnosed by liver biopsy.

\section{Methods}

Twenty-eight NASH patients (mean age 41.6 $\pm 9.8,16$ male) who were examined at the Kayseri Education and Research

Address for Correspondence: Dr. Ahmet Oğuz Baktır, Sanayi Mah. Atatürk Bulvarı Hastane Cad. No:78, 38010, Kocasinan/Kayseri-Türkiye

Phone: +90 3523368888 Fax: +90352 3207313 E-mail: aobaktir@gmail.com

Accepted Date: 17.01.2014 Available Online Date: 08.04.2014

(C) Copyright 2015 by Turkish Society of Cardiology - Available online at www.anakarder.com DOI:10.5152/akd.2014.5212 
Hospital Gastroenterology outpatient clinic and diagnosed by liver biopsy were included in this study. 28 sex and age matched healthy volunteers without abnormal biochemical and ultrasonography were selected as control group. Informed consent forms were obtained from every individual enrolled and the study was approved by the local Ethics Committee of Kayseri Education and Research Hospital.

The exclusion criteria were as follows; angina and angina equivalent symptoms, history of abnormal cardiovascular stress test and abnormal myocardial scintigraphy, an LVEF lower than $50 \%$, individuals with structural heart disease, a documented history of coronary and peripheric vascular diseases, diabetes mellitus, body mass index (BMI) $>30 \mathrm{~kg} / \mathrm{m}^{2}$, hypertension; defined as a systolic blood pressure value of $>140 \mathrm{~mm} \mathrm{Hg}$ and diastolic blood pressure value of $>90 \mathrm{~mm} \mathrm{Hg}$ after averaging three separate blood pressure measurements taken at 10 minute intervals and patients receiving antihypertensive treatment, restrictive and obstructive pulmonary disease, individuals with systemic and metabolic diseases that could adversely affect the cardiac structure and functions, and smoking.

All individuals' blood pressures, pulses, and anthropometric measures were recorded before echocardiography. BMI were derived from anthropometric measures. Biochemical parameters were obtained from previous recording of venous blood samples drawn after an 8 hour fasting period at gastroenterology outpatient clinic. HOMA-IR was calculated by formula.

Echocardiography was performed in the left lateral decubitus position with the GE-Vingmed Vivid 7 system (GE-Vingmed Ultrasound AS, Horten, Norway) ultrasound and a 3S-RS (3.5 $\mathrm{mhz}$ ) probe. All echocardiographic examinations were performed by two experienced cardiologists who were unaware of the clinical data of the groups. Images were obtained from parasternal and apical view using 2-D, M-Mode and Doppler echocardiographic techniques. The 2-D, M-mode and Doppler echocardiographic examinations were performed according to the guidelines of American Society of Echocardiography (7). The left atrial (LA) volume was determined using the biplane area-length method after measuring the area and the long-axis length of the LA at ventricular end-systole in the apical 4-chamber and 2-chamber views. The LA volume was then calculated according to the biplane area-length formula. The LA volume index was defined after the correction for body surface area (7).

Tissue Doppler imaging (TDI) was performed from the apical four-chamber view using a pulsed-wave Doppler with a $3 \mathrm{~mm}$ sample volume placed on the septal and lateral mitral annulus. All of the annular velocities and time intervals of tissue Doppler analysis were calculated as an average of the two annular sites. Pulsed-wave TDI examinations were performed according to the guidelines of American Society of Echocardiography (8). The ratios between the mitral early diastolic flow velocity $(E)$, the mitral annular early diastolic myocardial velocity ( $\left.E^{\prime}\right)$. The averages of three consecutive cycles were measured for all echocardiographic data.
A software package (Echopac PC, version 8.0, GE Healthcare) was used to perform offline analyses of STE from apical and parasternal short-axis views. Standard grayscale 2-D images were obtained from the apical 4, 2, 3 chamber views and the parasternal short-axis views at the papillary muscle level at a frame rate of 70-90 frame(s). Myocardial strain $\left({ }_{S}\right)$ and strain rate $\left({ }_{S R}\right)$ were measured as previously described (9). After end-expiratory breath holding 3 consecutive cardiac cycles were recorded and stored for the offline analysis. Endocardial border of the left ventricule (LV) was traced manually at the end of the end-systolic frame. Software automatically created a region of interest on the entire wall and selected natural acoustic markers. Via frame by frame tracking of these markers during the cardiac cycle, measurement of $S$ and $S R$ at any point of the myocardium was done. The circumferential strain $\left(C_{S}\right)$, systolic strain rate $\left(C_{S R-S}\right)$, early diastolic strain rate $\left(\mathrm{C}_{S R-E}\right)$, and the late diastolic strain rate $\left(C_{S R-A}\right)$ values of the LV were obtained using the graphics generated by the software through the evaluation of the analyses belonging to the six segments. Because the graphics created by the program to depict the circumferential functions could not be generated for the radial functions following the analysis, the arithmetical average of the radial strain and the strain rate values were found by calculating the arithmetic average of the radial strain $\left(R_{S}\right)$, systolic strain rate $\left(R_{S R-S}\right)$, early diastolic strain rate $\left(R_{S R-E}\right)$ and the late diastolic strain rate $\left(R_{S R-A}\right)$ values belonging to the six segments. The longitudinal strain $\left(L_{S}\right)$, longitudinal systolic strain rate $\left(L_{S R-S}\right)$, early diastolic strain rate $\left(L_{S R-E}\right)$ and the late diastolic strain rate $\left(L_{S R-A}\right)$ were measured from 6 LV walls from the apical 4, 2, 3 chamber views recordings. The averages of these measurements were used for the comparison of the NASH patients with the controls. Radial strain $\left(R_{S}\right)$, radial systolic strain rate $\left(R_{\text {SR-S }}\right)$, early diastolic strain rate $\left(R_{\text {SR-E }}\right)$ and the late diastolic strain rate $\left(R_{S R-A}\right)$ were obtained from the parasternal LV short-axis view at the level of the papillary muscles. The $C_{S}$, $\mathrm{C}_{\text {SR-S }}, \mathrm{C}_{\text {SR-E}}, \mathrm{C}_{\text {SR-A }}$ were also obtained from the same views and the calculation of average values used for the compassion.

\section{Statistical analysis}

All analyses were carried out using SPSS 16.0 for Windows (SPSS Inc., Chicago, IL, USA). Continuous variables were given as mean \pm standard deviation; categorical variables were defined as percentages. The variables were investigated using Kolmogorov-Smirnov test to determine whether or not they are normally distributed. Independent samples test was used to compare continuous variables between the two groups. Nonparametric values were compared with Mann-Whitney U test. Chi-square test was used to compare categorical data. A multiple linear regression model was used to identify the statistical significance of relationships between selected variables and $R_{S}$ and $L_{S}$. The Blant-Alman analysis method was used to determine inter and intraobserver variability. A two tailed $p$ value $<0.05$ was considered as significant. 


\section{Results}

A total of 56 subjects consisting of 28 healthy individuals and $28 \mathrm{NASH}$ patients were evaluated in the study. Detailed demographic, clinical, biochemical variables of the two groups are presented in Table 1. Detailed parameters of 2-D, pulse Doppler and TDI of the two groups are given in Table 2. Isovolumic relaxation time (IVRT) and deceleration time (DT) were higher in NASH patients. Mean S and mean E tissue Doppler values were lower in patients with NASH but E/E' and E/A ratio were similar between two groups.

\section{Systolic, diastolic strain and strain rate parameters}

Detailed 2D-STE values of the all groups are given in Table 3. $\mathrm{R}_{\mathrm{S}}$ was lower in the NASH group than in the healthy individuals and differences were statistically significant. $R_{S R-S}$ values were similar but $R_{S R-E}, R_{S R-E / A}$ values were significantly lower and $\mathrm{R}_{\text {SR-A }}$ was higher in the NASH patients. There were no significant differences in $C_{S}, C_{S R-S}, C_{S R-E}, C_{S R-A}$ and $C_{S R-E / A}$ values among the two groups. The most impressive results were obtained from longitudinal strain and strain rate parameters. $L_{S}$, $\mathrm{L}_{\text {SR-S, }} \mathrm{L}_{\mathrm{SR}-\mathrm{E}} \mathrm{L}_{\text {SR-A, }}$ values were significantly lower in $\mathrm{NASH}$ group when compared with healthy controls (Table 3). Comparison of $L_{S}, C_{S}$ and $R_{S}$ were given in Figure 1. Linear regression analysis showed that $R_{S}$ was not associated with diastolic blood pressure (Coefficient b: $0.053, p=0.694$ ), total cholesterol (Coefficient $b$ : 0.014, $p=0.947$ ) and LDL cholesterol (Coefficient b: 0.170, $p=0.383$ ). Also $\mathrm{L}_{S}$ was not associated with diastolic blood pressure (Coefficient b: 0.028, $p=0.709$ ), total cholesterol (Coefficient $b$ : 0.470, $p=0.686$ ) and LDL cholesterol (Coefficient b: 0.030, p=0.781) (Table 4, 5).

\section{Discussion}

Results of present study demonstrated that longitudinal and radial strain were lower in NASH patients.

Insulin resistance (IR), is the main pathophysiological mechanism of NASH (10). Hepatic steatosis leads to hepatic IR and impaired suppression of hepatic glucose production, which leads to hyperglycemia in NAFLD patients. Subsequently com- pensatory hyperinsulinemia and worsening of systemic and cardiac IR occurs (11-13). Myocardial IR affects cardiomyocytes in several mechanisms. Firstly, products of free fatty acids (FFA) excess metabolism (14) generates a well described phenomenon "cardiac lipotoxicity". In patients with nonischemic chronic heart failure with obesity and/or diabetes, lipotoxicity also plays an essential role in the pathogenesis of cardiomyopathy which is a leading cause of death (15-17). Especially, in diabetic patients liver fat content independently indicates myocardial IR and impaired coronary functional capacity (18). Present study investigated nondiabetic patients, but HOMA-IR levels indicating IR were higher than the control group as expected. We can speculate that in NASH myocardial impairment may occur due to myocardial IR. Secondly, ceramide accumulation formed via de novo synthesis from FFA, plays a central role in apoptosis of cardiomyocytes. Structural alterations in mitochondria can reduce cardiac function by providing an insufficient supply of ATP to cardiac myocytes or by increasing reactive oxygen spe-

Table 1. Demographic, clinical, biochemical variables of the NASH and control groups

\begin{tabular}{|c|c|c|c|}
\hline & NASH & Control & $\boldsymbol{P}$ \\
\hline Age & $41.6 \pm 9.8$ & $41.2 \pm 9$ & 0.877 \\
\hline BMI, $\left(\mathrm{kg} / \mathrm{m}^{2}\right)$ & $27.7 \pm 1.6$ & $26.7 \pm 1.7$ & 0.053 \\
\hline HOMA-IR & $5.29 \pm 4.3$ & $2.1 \pm 1.3$ & $<0.001$ \\
\hline Systolic BP, mm Hg & $120.7 \pm 9.3$ & $120.3 \pm 12$ & 0.902 \\
\hline Diastolic BP, mm Hg & $79.2 \pm 5$ & $75.0 \pm 9.5$ & 0.042 \\
\hline Fasting glucose, $\mathrm{mg} / \mathrm{dL}$ & $95.1 \pm 18.1$ & $90.0 \pm 6.6$ & 0.171 \\
\hline Total cholesterol, mg/dL & $233.4 \pm 46.2$ & $198.3 \pm 15.9$ & $<0.001$ \\
\hline LDL-cholesterol, mg/dL & $149.0 \pm 35$ & $129.8 \pm 21.8$ & 0.022 \\
\hline HDL-cholesterol, mg/dL & $47.0 \pm 9.4$ & $45.4 \pm 7.3$ & 0.482 \\
\hline Trigliseride, $\mathrm{mg} / \mathrm{dL}$ & $217.0 \pm 123.5$ & $167.3 \pm 47.9$ & 0.063 \\
\hline AST, U/L & $42.7 \pm 9.6$ & $33.0 \pm 5.5$ & $<0.001$ \\
\hline ALT, U/L & $44.5 \pm 9.3$ & $33.4 \pm 6.2$ & $<0.001$ \\
\hline $\mathrm{GGT}, \mathrm{U} / \mathrm{L}$ & $64.7 \pm 42.7$ & $39.2 \pm 8.8$ & $=0.04$ \\
\hline \multicolumn{4}{|c|}{$\begin{array}{l}\text { Data are expressed as mean } \pm \text { SD } \\
\text { ALT - alanine transaminase; AST - aspartic acid transaminase; BMI - body mass } \\
\text { index; BP - blood pressure; GGT - gamma-glutamyltransferase; HDL - high density } \\
\text { lipoprotein; LDL - low density lipoprotein }\end{array}$} \\
\hline
\end{tabular}

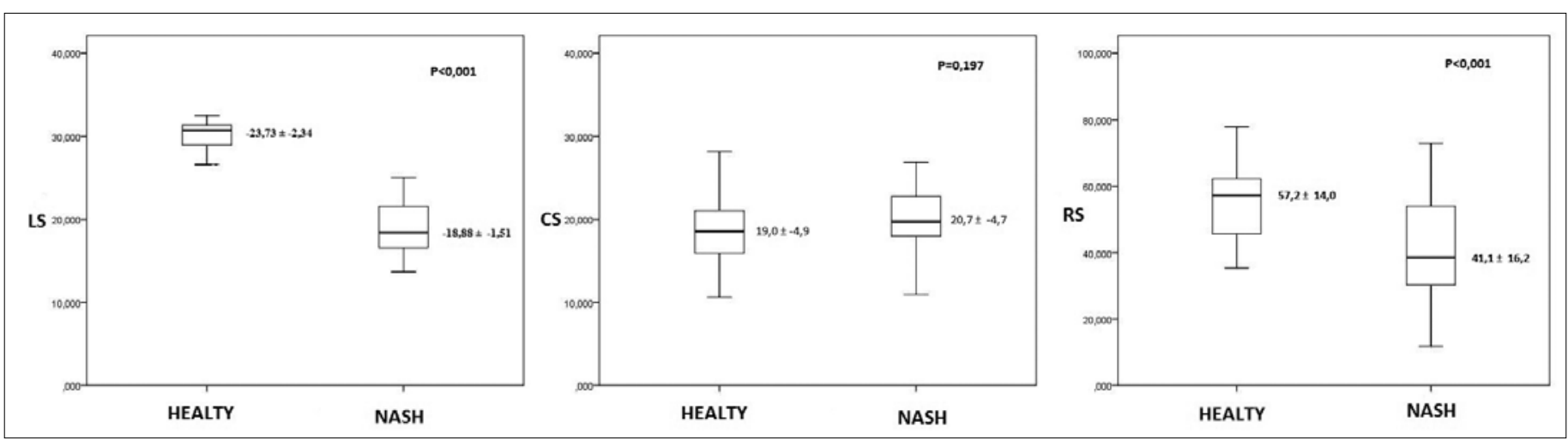

Figure 1. Comparison of longitudinal strain (LS), circumferential strain (CS) and radial strain (RS) 
Table 2. 2-D, M-mode, Doppler and tissue Doppler echocardiography parameters of the patients and the control group

\begin{tabular}{|l|c|c|c|}
\hline & NASH & Control & $\boldsymbol{P}$ \\
\hline LVDD, mm & $46.5 \pm 4.7$ & $45.9 \pm 3.8$ & 0.624 \\
\hline LVSD, mm & $29.1 \pm 3.6$ & $29.0 \pm 2.9$ & 0.936 \\
\hline IVSDD, mm & $9.9 \pm 1.3$ & $8.6 \pm 0.8$ & $<0.001$ \\
\hline PWDD, mm & $10.2 \pm 1.4$ & $8.7 \pm 0.8$ & $<0.001$ \\
\hline EF, $\%$ & $66.7 \pm 5.2$ & $65.7 \pm 2.4$ & 0.385 \\
\hline LA, mm & $33.8 \pm 3.1$ & $32.0 \pm 3.4$ & 0.043 \\
\hline LAVI, mL/m & $19.6 \pm 1.7$ & $18.8 \pm 1.9$ & 0.107 \\
\hline Mit E, m/s & $0.72 \pm 0.15$ & $0.80 \pm 0.14$ & 0.038 \\
\hline Mit A, m/s & $0.67 \pm 0.14$ & $0.67 \pm 0.16$ & 0.897 \\
\hline Mit E/A, ratio & $1.13 \pm 0.39$ & $1.23 \pm 0.30$ & 0.242 \\
\hline E/E', ratio & $6.93 \pm 1.6$ & $6.38 \pm 1.33$ & 0.170 \\
\hline Mean S, m/s & $0.08 \pm 0.01$ & $0.12 \pm 0.02$ & $<0.001$ \\
\hline Mean E, m/s & $0.11 \pm 0.03$ & $0.13 \pm 0.02$ & 0.012 \\
\hline IVRT, ms & $83.3 \pm 13.0$ & $70.6 \pm 12.4$ & 0.001 \\
\hline IVCT, ms & $58.2 \pm 14.5$ & $63.1 \pm 7.1$ & 0.118 \\
\hline DT, ms & $219.6 \pm 45.4$ & $160.1 \pm 31.3$ & $<0.001$ \\
\hline Dar are & & & \\
\hline
\end{tabular}

Data are expressed as mean \pm SD

DT - deceleration time; E/A - ratio between diastolic early and late-diastolic mitral inflow velocities; $E / E^{\prime}$ - ratio between early-diastolic mitral inflow velocity and earlydiastolic annular velocity; EF - ejection fraction; IVCT - isovolumic contraction time; IVSDD - interventricular septum diastolic thickness diameter; IVRT - isovolumic relaxation time; LA - left atrium; LAVI - left atrial volume index; LVDD - left ventricular diastolic diameter; LVSD - left ventricular systolic diameter; Mean S - systolic velocity on tissue Doppler echocardiography; Mean E - early diastolic velocity on tissue Doppler echocardiography; PWDD - posterior wall diastolic thickness diameter

Table 4. Linear regression analysis showing relationships between several variables and $\mathbf{R}_{\mathbf{S}}$

\begin{tabular}{|l|c|c|c|}
\hline Variables & Coefficient b & $\mathbf{9 5 \%} \mathbf{C l}$ & $\boldsymbol{P}$ \\
\hline Diastolic BP & 0.053 & $0.607-0.467$ & 0.694 \\
\hline Total cholesterol & 0.014 & $0.195-0.182$ & 0.947 \\
\hline LDL-cholesterol & 0.170 & $0.317-0.124$ & 0.383 \\
\hline $\mathrm{R}_{\mathrm{S}}$ - radial strain & & \\
\hline
\end{tabular}

Table 5. Linear regression analysis showing relationships between several variables and $L_{S}$

\begin{tabular}{|l|c|c|c|}
\hline Variables & Coefficient b & $\mathbf{9 5 \%}$ Cl & $\boldsymbol{P}$ \\
\hline Diastolic BP & 0.028 & $0.104-0.152$ & 0.709 \\
\hline Total cholesterol & 0.470 & $0.050-0.033$ & 0.686 \\
\hline LDL-cholesterol & 0.030 & $0.042-0.055$ & 0.781 \\
\hline L $_{\text {S }}$ longitudinal strain & \multicolumn{4}{|l}{} \\
\hline
\end{tabular}

cies (ROS) production, which has been associated with increased apoptosis, DNA damage and decreased DNA repair (19). Furthermore, ROS and reactive nitrogen species (RNS) triggers the activation of inflammatory pathways $(20,21)$. Conventional echocardiografic imaging parameters of left ventricular (LV) function like ejection fraction (EF) may be in normal limits in patients with NAFLD. In addition to conventional echo-
Table 3. Global strain and strain rate parameters of the patients and the control group

\begin{tabular}{|c|c|c|c|}
\hline & NASH & Control & $\boldsymbol{P}$ \\
\hline \multicolumn{4}{|l|}{ Radial } \\
\hline $\mathrm{S}(\%)$ & $41.1 \pm 16.2$ & $57.2 \pm 14.0$ & $<0.001$ \\
\hline SRS (1/s) & $2.34 \pm 0.75$ & $2.30 \pm 0.61$ & 0.789 \\
\hline SRE (1/s) & $-1.63 \pm-0.57$ & $-2.23 \pm-0.72$ & 0.001 \\
\hline SRA $(1 / \mathrm{s})$ & $-1.85 \pm-0.76$ & $-1.38 \pm-0.55$ & 0.011 \\
\hline SR E/A & $1.07 \pm 0.62$ & $1.96 \pm 1.12$ & 0.001 \\
\hline \multicolumn{4}{|c|}{ Circumferential } \\
\hline $\mathrm{S}(\%)$ & $-20.7 \pm-4.7$ & $-19.0 \pm-4.9$ & 0.197 \\
\hline SRS (1/s) & $-1.32 \pm-0.43$ & $-1.18 \pm-0.48$ & 0.252 \\
\hline SRE (1/s) & $1.42 \pm 0.62$ & $1.52 \pm 0.71$ & 0.558 \\
\hline SRA (1/s) & $0.83 \pm 0.45$ & $0.70 \pm 0.44$ & 0.284 \\
\hline SRE/A & $2.04 \pm 0.90$ & $2.52 \pm 1.13$ & 0.082 \\
\hline \multicolumn{4}{|c|}{ Longitudinal } \\
\hline GLS (\%) & $-18.88 \pm-1.51$ & $-23.73 \pm-2.34$ & $<0.001$ \\
\hline GLS2CH & $-18.52 \pm-2.32$ & $-23.79 \pm-3.11$ & $<0.001$ \\
\hline GLS3CH & $-19.26 \pm-2.10$ & $-23.19 \pm-2.95$ & $<0.001$ \\
\hline GLS4CH & $-18.63 \pm-1.95$ & $-24.21 \pm-2.82$ & $<0.001$ \\
\hline SRS $(1 / \mathrm{s})$ & $-1.14 \pm-0.20$ & $-1.73 \pm-0.28$ & $<0.001$ \\
\hline $\operatorname{SRE}(1 / \mathrm{s})$ & $1.20 \pm 0.38$ & $2.35 \pm 0.55$ & $<0.001$ \\
\hline $\operatorname{SRA}(1 / \mathrm{s})$ & $0.88 \pm 0.26$ & $1.47 \pm 0.37$ & $<0.001$ \\
\hline SRE/A & $1.45 \pm 0.55$ & $1.68 \pm 0.53$ & 0.106 \\
\hline \multicolumn{4}{|c|}{$\begin{array}{l}\text { Data are expressed as mean } \pm \text { SD and } n(\%) \\
\text { A - late diastolic; E - early diastolic; GLS - global longitudinal strain; GLS2CH-GLS3CH } \\
\text { GLS4CH - Global longitudinal strain of apical-4, 2, } 3 \text { chambers; S - systolic; S }(\%) \text { - } \\
\text { strain; SR - strain rate }\end{array}$} \\
\hline
\end{tabular}

cardiography, studies inspecting alterations of myocardial energy metabolism by magnetic resonance spectroscopy also showed that LV morphology and function was normal in nondiabetic NAFLD patients (22). However, subclinical LV impairment due to IR can be detected by advanced echocardiographic features like STE in NASH patients without morbid obesity, hypertension and diabetes, as in our study.

The conventional indices of global LV systolic and diastolic function, like EF and volumes have some disadvantages. These are load dependency, measurement errors, insufficient image quality. TDI is an other useful echocardiographic technique employing the Doppler principle to measure the velocity of myocardial segments and other cardiac structures which is load independent. But TDI also has some limitations, like angle dependency of the ultrasound beam, the complex rotational and translational movements of the heart. 2D-STE is a new imaging modality which calculates myocardial velocities and deformation parameters like strain and strain rate. Strain is a dimensionless index of myocardial deformation and is usually expressed in percent $(\%)$. Strain rate is the difference of strain in a time interval. Since STE was introduced in 2004, it is well known that strain and strain rate parameters provide important insights into 
systolic and diastolic function, ischaemia, myocardial mechanics and many other pathophysiological conditions of the heart. When left ventricular impairment begins, compensatory mechanisms can still sustain the normal stroke volume. 2D-STE can detect reduced contractility in patients with normal ejection fraction before changes in myocardial tissue velocities and other traditional parameters of systolic function (23).

Previous studies mostly included NAFLD patients who were diagnosed and scored by ultrasonography features (24). And demonstrated that non-diabetic subjects with NAFLD had early alterations especially in LV diastolic function detected by TDI. Some of them did not found any relationship between NAFLD and systolic tissue velocities (4). Fotbolcu et al. (25) reported LV diastolic and systolic dysfunction by TDI, and their parameters represented lower mean S, E' tissue velocities and longer IVRT compared with control subjects as in ours. But we found mean $S$ values lower than their findings and their patients selected to study were NAFLD patients diagnosed by abdominal ultrasonography.

In a recent study in obese pediatric patients, investigators demonstrated that obese adolescents with NAFLD have greater abnormalities in cardiac function, manifested by decreased systolic and diastolic myocardial strain and strain rate than obese adolescents who have normal IHTG content. In addition, obese adolescents with NAFLD were independent of traditional cardiac risk factors (26). Our results demonstrated that in addition to measurement of LV global $L_{S}$ and $L_{S R S}$, $R_{S}$ by speckle tracking analyses were also lower when compared with control subjects. Furthermore, $\mathrm{R}_{\mathrm{SRE}}$ and $\mathrm{R}_{\mathrm{SRE} / \mathrm{A}}$ were also reduced which indicate LV diastolic dysfunction (27). These 2D-STE results may reflect the consequence of further impairment of LV systolic and diastolic function compared with studies investigated NAFLD patients. Because of advanced necroinflammatory situation, advanced impairment of ventricular function may be detected by STE in NASH. Furthermore progression of NAFLD and cardiac influences may be recognized noninvasively by STE.

In another study by STE, Bonapace et al. (28) reported that NAFLD patients had significantly higher $L_{E / S R-E}$ and tended to have lower $L_{S R-E}$ and $L_{S R A}$ by measurements of LV global longitudinal strain and strain rate by speckle tracking analyze. But were not statistically significant except $L_{E / S R E}$ which were a parameter of diastolic function. However, patients included in that study were NAFLD patients with type 2 diabetes and they concluded that NAFLD may contribute to impairment of LV function which was already impaired in type 2 diabetes (28). Hallsworth et al. (29) examined cardiac status in a clinical group of NAFLD patients, using the combined techniques at 3.0T of phosphorus spectroscopy, cardiac tagging and cine MRI to measure cardiac energetics, strain and morphology. They concluded that in the absence of overt cardiac disease, longitudinal shortening was reduced. Differently, NAFLD was defined as $>5 \%$ intrahepatic lipid.

When compared with previous studies, our study group is a more specific, biopsy-proven necroinflammatory form of NAFLD without type 2 diabetes. Reduced radial and longitudinal strain/ strain rate datas evidently shows that as the disease advances, additional impairment in LV systolic function occurs. Mediators from the steatotic-inflamed liver, the contribution of insulin resistance, ROS, RNS and products of FFA excess metabolism in $\mathrm{NASH}$ may yield to further cardiac impairment (28).

There were significant difference in the level of cholesterol, LDL and diastolic BP between the groups of control and the patients. But linear regression analyses revealed that level of cholesterol, LDL and diastolic BP were not associated with $\mathrm{R}_{S}$ and $\mathrm{L}_{S}$.

\section{Study limitations}

The main limitation of this study was the low number of patients, but patients considered in this study were biopsy proven and without cardiovascular risk factors. Although there were not differences between systolic and diastolic blood pressures, we did not take 24-h ambulatory blood pressure recordings. Therefore we are not able to evaluate possible increases in blood pressure in NASH patients. The aim of our study was to evaluate the relationship between the NASH and the myocardial function by using the 2D-STE method, other biochemical parameters of myocardial function like brain natriuretic peptide did not evaluated. Comparison of another group of patients which includes simple hepatic steatosis with other groups may reflect the progression of myocardial influences in NAFLD patients.

\section{Conclusion}

It may be concluded that the LV longitudinal and radial systolic functions may deteriorate in patients with NASH without an apparent decrease in the LVEF. According to our results, insulin resistance in NASH could be the main mechanism for such LV changes. Therefore, in patients with NASH, besides the conventional echocardiography and TDI methods, the presence of subclinical myocardial dysfunction can be determined in detail during the early stages through the 2D-STE method.

Conflict of interest: None declared.

Peer-review: Externally peer-reviewed.

Authorship contributions: Concept - A.O.B., B.Ş.; Design H.A., A.K., H.K.; Supervision - H.A.; Resource - A.O.B., B.Ş.; Materials - A.O.B., B.S.; Data collection \&/or processing - Y.D., A.E., H.A.; Analysis \&/or interpretation - A.O.B., B.Ş., R.E.A.; Literature search - H.S., Y.D.; Writing - A.O.B.; Critical review B.Ş., R.E.A.

\section{References}

1. Cheung 0, Kapoor A, Puri P, Sistrun S, Luketic VA, Sargeant CC, et al. The impact of fat distribution on the severity of nonalcoholic fatty liver disease and metabolic syndrome. Hepatology 2007; 46: 1091-100. [CrossRef] 
2. Ekstedt M, Franzén LE, Mathiesen UL, Thorelius L, Holmqvist M, Bodemar G, et al. Long-term follow-up of patients with NAFLD and elevated liver enzymes. Hepatology 2006; 44: 865-73. [CrossRef]

3. Alper AT, Hasdemir H, Şahin S, Ontürk E, Akyol A, Nurkalem Z, et al. The relationship between nonalcoholic fatty liver disease an $d$ the severity of coronary artery disease in patients with metabolic syndrome. Turk Kardiyol Dern Ars 2008; 36: 376-81.

4. Goland S, Shimoni S, Zornitzki T, Knobler H, Azoulai O, Lutaty G, et al. Cardiac abnormalities as a new manifestation of nonalcoholic fatty liver disease: echocardiographic and tissue Doppler imaging assessment. J Clin Gastroenterol 2006; 40: 949-55. [CrossRef]

5. Amundsen BH, Helle-Valle T, Edvardsen T, Torp H, Crosby J, Lyseggen $E$, et al. Noninvasive myocardial strain measurement by speckle tracking echocardiography: validation against sonomicrometry and tagged magnetic resonance imaging. J Am Coll Cardiol 2006; 47: 789-93. [CrossRef]

6. Sert A, Aypar E, Pirgon 0, Yılmaz H, Odabaş D, Tolu I. Left ventricular function by echocardiography, tissue Doppler imaging, and carotid intima-media thickness in obese adolescents with nonalcoholic fatty liver disease. Am J Cardiol 2013; 112: 436-43. [CrossRef]

7. Lang RM, Bierig M, Devereux RB, Flachskampf FA, Foster $E$, Pellikka PA, et al. Chamber Quantification Writing Group, et al. Recommendations for chamber quantification: a report from the American Society of Echocardiography's Guidelines and Standards Committee and the Chamber Quantification Writing Group, developed in conjunction with the European Association of Echocardiography, a branch of the European Society of Cardiology. J Am Soc Echocardiogr 2005; 1440-63. [CrossRef]

8. Quinones MA, Otto CM, Stoddard M, Waggoner A, Zoghbi WA. Recommendations for quantification of Doppler echocardiography: a report from the Doppler Quantification Task Force of the Nomenclature and Standards Committee ofthe American Society of Echocardiography. J Am Soc Echocardiogr 2002; 15: 167-84. [CrossRef]

9. Altekin RE, Yanıkoğlu A, Baktır A0, Karakaş MS, Özel D, Çilli A, et al. Assessment of subclinical left ventricular dysfunction in obstructive sleep apnea patients with speckle tracking echocardiography. Int J Cardiovasc Imaging 2012; 28: 1917-30. [CrossRef]

10. Matthews DR, Hosker JP, Rudenski AS, Naylor BA, Treacher DF, Turner RC. Homeostasis model assessment: insulin resistance and $\beta$-cell function from fasting plasma glucose and insulin concentrations in man. Diabetologia 1985; 28: 412-9. [CrossRef]

11. Korenblat KM, Fabbrini E, Mohammed BS, Klein S. Liver, muscle, and adipose tissue insulin action is directly related to intrahepatic triglyceride content in obese subjects. Gastroenterology 2008; 134 : 1369-75. [CrossRef]

12. Fabbrini E, Magkos F, Mohammed BS, Pietka T, Abumrad NA, Patterson BW, et al. Intrahepatic fat, not visceral fat, is linked with metabolic complications of obesity. Proc Natl Acad Sci U S A 2009; 106: 15430-5. [CrossRef]

13. Salamone F, Bugianesi E. Nonalcoholic fatty liver disease: the hepatic trigger of the metabolic syndrome. J Hepatol 2010; 53: 1146-7. [CrossRef]

14. Unger RH, Orci L. Lipotoxic diseases of nonadipose tissues in obesity. Int J Obes Relat Metab Disord 2000; 24: 28-32. [CrossRef]
15. Brindley DN, Kok BP, Kienesberger PC, Lehner R, Dyck JR. Shedding light on the enigma of myocardial lipotoxicity: the involvement of known and putative regulators of fatty acid storage and mobilization. Am J Physiol Endocrinol Metab 2010; 298: 897908. [CrossRef]

16. Mellor KM, Ritchie RH, Delbridge LM. Reactive oxygen species and insülin resistant cardiomyopathy. Clin Exp Pharmacol Physiol 2010; 37: 222-8. [CrossRef]

17. McGavock JM, Victor RG, Unger RH, Szczepaniak LS. Adiposity of the heart, revisited. Ann Intern Med 2006; 144: 517-24. [CrossRef]

18. Lautamäki R, Borra R, lozzo P, Komu M, Lehtimäki T, Salmi M, et al. Liver steatosis coexists with myocardial insulin resistance and coronary dysfunction in patients with type 2 diabetes. Am J Physiol Endocrinol Metab 2006; 291: 282-90. [CrossRef]

19. Boudina S, Abel ED. Diabetic cardiomyopathy revisited. Circulation 2007; 115: 3213-23. [CrossRef]

20. Marra F. Nuclear factor-kappaB inhibition and non-alcoholic steatohepatitis: inflammation as a target for therapy. Gut 2008; 57 : 570-2. [CrossRef]

21. Videla LA, Tapia G, Rodrigo R, Pettinelli P, Haim D, Santibañez C, et al. Liver NF-kappaB and AP-1 DNA binding in obese patients. Obesity (Silver Spring) 2009; 17: 973-9. [CrossRef]

22. Perseghin G, Lattuada G, De Cobelli F, Esposito A, Belloni E, Ntali G, et al. Increased mediastinal fat and impaired left ventricular energy metabolism in young men with newly found fatty liver. Hepatology 2008; 47: 51-8. [CrossRef]

23. Edvardsen T, Helle-Valle T, Smiseth OA. Systolic dysfunction in heart failure with normal ejection fraction: speckle-tracking echocardiography. Prog Cardiovasc Dis 2006; 49: 207-14. [CrossRef]

24. Hamaguchi M, Kojima T, Itoh Y, Harano Y, Fujii K, Nakajima T, et al. The severity of ultrasonographic findings in nonalcoholic fatty liver disease reflects the metabolic syndrome and visceral fat accumulation. Am J Gastroenterol 2007; 102: 2708-15. [CrossRef]

25. Fotbolcu H, Yakar T, Duman D, Karaahmet T, Tigen K, Çevik C, et al. Impairment of the left ventricular systolic and diastolic function in patients with non-alcoholic fatty liver disease. Cardiol J 2010; 17: 457-63.

26. Singh GK, Vitola BE, Holland MR, Sekarski T, Patterson BW, Magkos $F$, et al. Alterations in ventricular structure and function in obese adolescents with nonalcoholic fatty liver disease. J Pediatr 2013; 162: 1160-8. [CrossRef]

27. Støylen A, Slørdahl S, Skjelvan GK, Heimdal A, Skjaerpe T. Strain rate imaging in normal and reduced diastolic function: comparison with pulsed Doppler tissue imaging of the mitral annulus. J Am Soc Echocardiogr 2001; 14: 264-74. [CrossRef]

28. Bonapace S, Perseghin G, Molon G, Canali G, Bertolini L, Zoppini G, et al. Nonalcoholic fatty liver disease is associated with left ventricular diastolic dysfunction in patients with type 2 diabetes. Diabetes Care 2012; 35: 389-95. [CrossRef]

29. Hallsworth K, Hollingsworth KG, Thoma C, Jakovljevic D, MacGowan $\mathrm{GA}$, Anstee 0M, et al. Cardiac structure and function are altered in adults with non-alcoholic fatty liver disease. J Hepatol 2013; 58 : 757-62. [CrossRef] 